\title{
Development of an intelligent learning resource using computer simulation about optical communications
}

\section{Marcelo Mamud, Sandra Stump}

Marcelo Mamud, Sandra Stump, "Development of an intelligent learning resource using computer simulation about optical communications," Proc. SPIE 9666, 11th Education and Training in Optics and Photonics Conference, 96660W (5 June 2009); doi: 10.1117/12.2207979

Event: Eleventh International Topical Meeting on Education and Training in Optics and Photonics, 2009, St. Asaph, United Kingdom 


\title{
Development of an Intelligent Learning Resource using Computer Simulation about Optical Communications
}

\author{
Marcelo Mamud and Sandra Stump \\ Mackenzie Presbyterian University \\ Rua da Consolacao, 896 - Sao Paulo, Brazil
}

\begin{abstract}
In recent years there have been some proposals to develop educational tools using multimedia and interactive resources, however, most of them just transpose the traditional materials to the computer screen. The reason for this work is the gap of didactic materials to explore important subjects about photonics and optical communication systems, specially the lack of tools related to Erbium Doped Fiber Amplifier (EDFA) learning. The aim of this research is to provide at the LCMS MOODLE open platform an Intelligent Learning Resource to support EDFA study, providing a set of Learning Objects more suitable for the study of the base concepts needed to optimize the use of the computer simulation tool. The learning resource developed can stimulate the students to understand how amplifiers are designed for a practical application, and the parameters that should be considered in a project. The Artificial Intelligence techniques used for the development of the learning resource consider the learner differences in a way to adapt the system actions according to each student background.
\end{abstract}

Keywords - Intelligent Tutoring Systems; Learning Objects; Multiagent Systems; Conceptual Maps; Erbium Doped Fiber Amplifiers.

\section{INTRODUCTION}

The development and availability on Internet of educational tools allow the implementation of interactive and hypermedia projects for education that can provide to students the management of study according to their own learning rhythm. Facing those issues, this research presents the development of an Intelligent Learning Resource for Electric Engineering, Physics, and related fields, in which students can learn about optical communications, in particular Erbium Doped Fiber Amplifier (EDFA). The proposal is to give autonomy to the students, which manage their own study time, and fulfill the basement and prerequisites needed to understand the subject and complete the tasks proposed. Moreover, the learning resource proposes the navigation through a concept map based on a multiagent system architecture, providing an individual treatment according to each student profile.

This paper is organized as follows: at first, the main characteristics of Learning Objects, multimedia and interactive technologies, concept maps and the principles of learning by simulation are briefly presented. Next, the artificial intelligence theory of agent is reviewed followed by the design methodology and the development procedures. Then, the results are discussed and finally the conclusions and further works are exposed.

\section{THE REUSABLE LEARNING OBJECTS}

The Institute of Electrical and Electronics Engineers (IEEE) Learning Technology Standards Committee (LTSC) define Learning Objects as "...any entity, digital or non-digital, which can be used, re-used or referenced during technology supported learning" [1]. However, the amplitude of this definition requires some delimitation: those elements should be digital entities [2] and that should be characterized by metadata, that describes the learning object content. 
For a high availability of learning objects, it is appropriate to provide an infrastructure to keep and maintain them [3]. Usually the learning objects are published in Learning Object Repositories (LOR) or Learning Management and Content Systems (LCMS). The LCMS allows the management of learning objects and provide tools to students' to plan and run their individual studies, and also exchange information and knowledge with other students and professors, by e-mail, chat, forum in a collaborative environment [4].

Facing the potential, popularization and the growing number systems available, some initiatives have started with the objective of standardization and specification of learning objects, their building and identity. Those specifications are fundamental to enable reusability and interpretability of Learning Objects. Among existing standards, some can be distinguished as Sharable Content Object Reference Model (SCORM) [5]. The following technology resources can be added to the learning object concept in order to optimize the learning process.

\section{MULTIMEDIA AND INTERACTIVE RESOURCES}

The concept of multimedia in the context of education can be defined by [6] as a presentation material using the verbal form, as a printed or spoken text, and a pictorial form, that is to say, graphics, illustration, dynamic animation or video. The creation of both verbal and pictorial models on the students' mind helps them to associate new concepts to the ones previously learnt, culminating in the meaningful learning. Moreover, an interactive interface stimulates the students to have an active participation on the learning process. For so, the users are supposed to determinate a sequence of actions: act, comprehend and evaluate the system responses [7].

\section{CONCEPTUAL MAPS}

The concept maps were developed in the middle of the eighties motivated by the difficulty found by many students to have an effective learning process [8]. The idea is to connect new information to existing knowledge through a graphical representation of a person's understanding of a specific domain [9].

A concept map consists of a construction of concepts into a coherent hierarchy, linked together, forming propositions. A concept map can show visually the relationship between concepts, helping students to find new meanings [8].

\section{COMPUTER SIMULATION TOOLS}

The idea of learning by simulation can be considered a modern practical based learning methodology with some benefits that the new software technology can bring when compared to the traditional laboratory experiments, theoretical classes or the traditional teaching methodologies [10]-[11]. Among the advantages of using computer simulation tools in education, the students are given the possibility of changing the parameters of a system then evaluate the results in a real time and interactive way. It permits to create a cause-effect structure of the studied concepts on the students' mind [10].

Despite the long lasting discussion about using technology in education, it is known that the hopes and expectations of implementing revolutionary instructional materials in schools were unmet [6]. Still according to [6], it can be explained by the technology centered approach taken, that is to say, the students have been forced to adapt themselves to the new methodologies, stimulating negative feeling about the use of cutting edge technology in education.

\section{THE AGENT THEORY}

In this context the development of the artificial intelligence based systems are important in a way to adapt the system actions to each student needs. The goal of these systems is to adopt the human as model to guide the behavior of the system. In some complex applications, such as in education, the computer needs to act by itself in order to solve a problem and achieve a goal. That is when the multiagent system theory can help in 
the insertion of intelligent behavior in the traditional instructional digital tools. Figure 1 shows the relation between an agent and the environment.

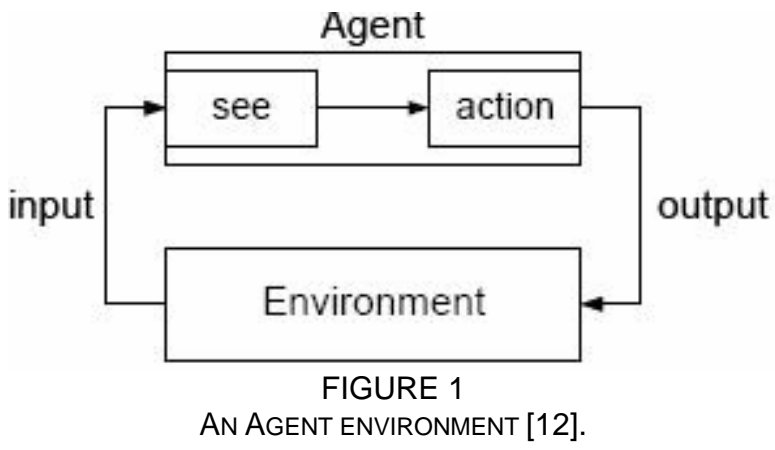

According to figure 1, it is possible to see that the environment is responsible for the input, that is to say when the agent percepts the environment state and the output, when the agent performs an action in the environment.

As mentioned before, the concept of agent is related to its interaction with the environment, but there is no universal definition for agents. According to [12]-[13] agents are able to percept the environment (by sensors) and act in this environment in an autonomous way. An agent can be compared to the classical expert systems, however, the main difference between them is the fact that not all the expert systems act directly in the environment [12].

\section{DEVELOPMENT OF THE PROJECT}

This paper presents the development of a learning resource that can observe the student background profile in order to fulfill the lack of concepts related to the subject chosen using learning objects. The strategy adopted to observe the learner background is based on the communication between the system and the user. In other words, the search for information about each student background is based on a test, but the interaction with the system can also provide new information about each concept studied. The use of the PTDS (Photonic Transmission Design Suite) [14] simulation tool requires a previous understanding of the base principles of EDFA, for so it is important to supply specific learning materials so that the students can get the advantages of having a project based learning using this worldwide popular simulation software. Figure 2 shows the architecture of the learning resource proposed.

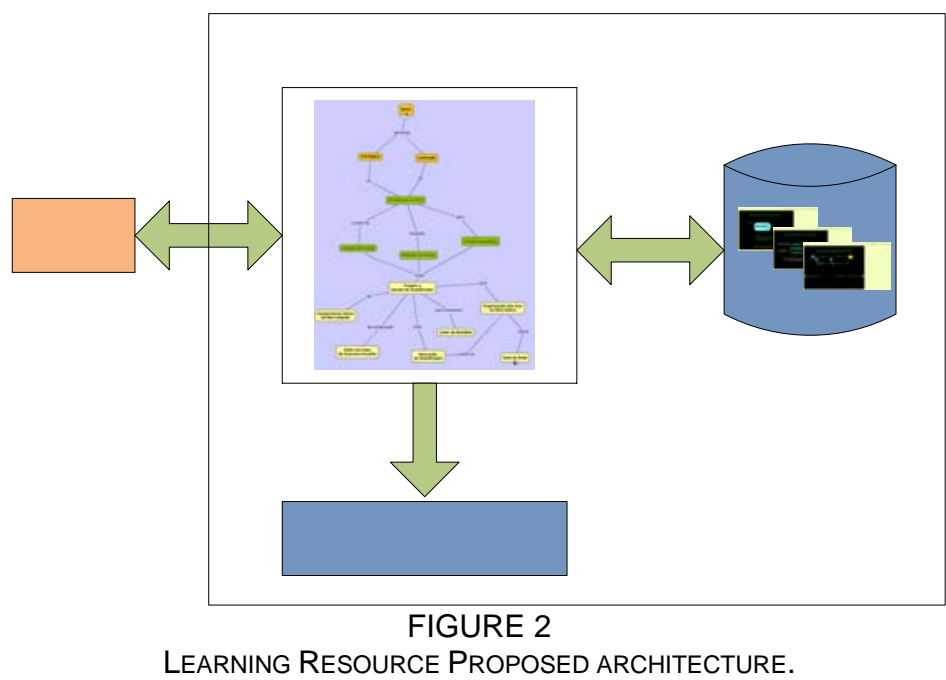


According to the architecture proposed, it is possible to identify three main modules of the system: the multiagent concept map within the connection to the LCMS Content Repository (Learning Objects) and the computer simulation activity.

\subsection{Concept Map}

The development of a concept map is very flexible, there is not only one way to produce a graphical representation of certain subject in a concept map [9]. The concept map proposed in this paper was produced according to the following steps.

At first, the main concepts related to EDFA were identified to be presented in the map labels. The preference is for using short words in the labels, but sometimes it was needed to use longer expressions in order to have the map correctly labeled. The second step is about the hierarchy of the concepts which were divided into three clusters. The first cluster is related to the factual information, such as the development of EDFA, advantages and limitation of using this technology in telecommunication systems. The second cluster of concepts is about the physics principles that should be known to understand how the EDFA works to amplify an optical signal. Finally, the third cluster is related to project and practical issues involving the EDFA technology. The concepts associated to the third cluster are mainly important to students who will develop new projects or solve problems in applications with optical communication devices. Each concept label in the concept map has an associated learning object, in case the student requires a deep study of any concept presented. The table I shows the classification of the learning objects developed, according to the hierarchy of concepts used to build up the concept map. These concepts should be read from the top to the bottom of the map and it was also used different colors according to each hierarchical level. This strategy was taken to guide the learners during the navigation and to make sure that the proposed hierarchy will be followed properly.

\begin{tabular}{lll}
\hline Cluster & Associated knowledge & Learning Object Title \\
\hline 1 & Factual Concepts & Development of EDFA technology \\
1 & Factual Concepts & Advantages of using EDFA \\
1 & Factual Concepts & Limitation of EDFA amplifiers \\
2 & Physical principles & Base EDFA working process \\
2 & Physical principles & Stimulated Emission \\
2 & Physical principles & Spontaneous Emission \\
2 & Physical principles & Energy Absorption \\
2 & Physical principles & Properties of the erbium ion \\
3 & Project based concepts & EDFA base parameters \\
3 & Project based concepts & Pumping Laser \\
3 & Project based concepts & Erbium Doped Fiber length \\
3 & Project based concepts & The erbium ion organization \\
3 & Project based concepts & The EDFA dynamic behavior \\
3 & Project based concepts & The amplifier saturation \\
\hline
\end{tabular}

Table 1 - Hierarchy of the Concepts

The next procedure in the development of the concept map is to connect the labeled concepts. In this project the labels were connected by lines, linking words or short verb expression as well as arrowheads. The importance of connecting labels properly is due to the fact that the linking words are responsible for creating meaning.

The concept map was built up with the IHMC CMap software toolkit [15] which was developed by the Institute for Human and Machine Cognition. Finally, the concept map was uploaded and implemented in the MOODLE learning environment [16].

\subsection{Computer Agents}

The agent theory culminated in the development of the Multiagent systems, such an important technique used in Distributed Artificial Intelligence (DAl) research area. The multiagent system architecture is composed 
of a society of agents working in a collaborative way towards the solution of a problem. For so, a multiagent environment should have a group of autonomous and distributed agents as well as a communication protocol to guarantee the interaction among the system agents and external agents either robots or humans, such as tutors or students [13].

This paper proposes the insertion of a society of agents in the concept map, in order to observe, collect information about the user background profile, and also act in the virtual environment, suggesting the study of the most appropriate learning objects. The use of artificial intelligence techniques within concept maps has been discussed for years due to the free style format that a concept map can take [9]. The insertion of multiagents is a proposal of joining the benefits of a concept map and the needs to adapt the tutoring system to each student profile by the artificial intelligence expertise.

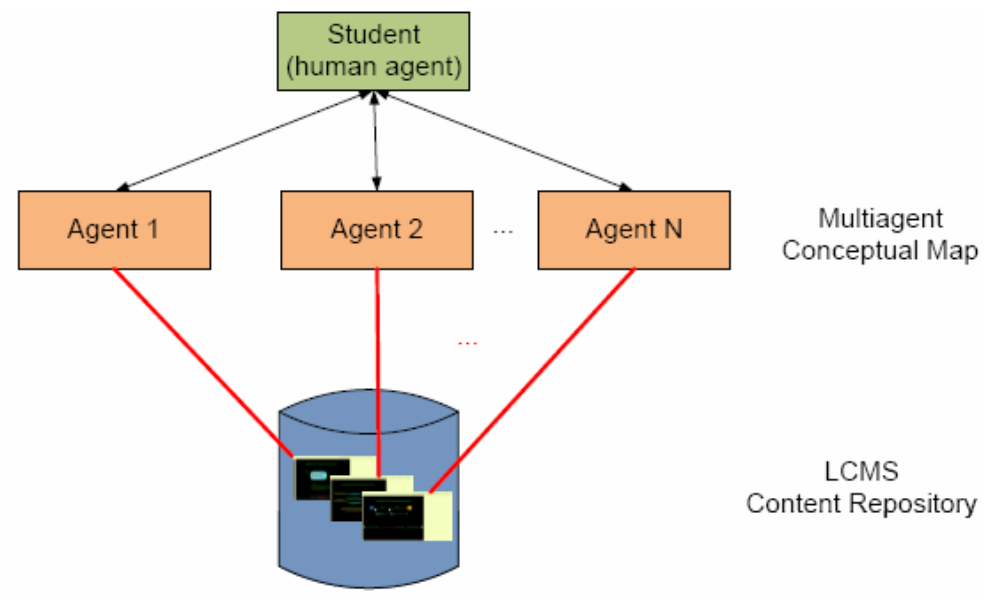

FIGURE 3

CENTRALIZED MULTIAGENT ARCHITECTURE.

The structure of the system proposed is based on a centralized multiagent architecture, as it is shown in figure 3. For so, one agent was built for each concept labeled in the concept map. It means that each agent is responsible for inferring whether the user shall study the associated learning object or not. That is when the human agent, performed by the student is in charge of coordinating the agent proposals [12].

The agents developed in this project can be classified as purely reactive agents [12]-[13]. The internal structure was composed by a production rule (if [condition], then [action]). It means that the purely reactive agent does not use historical data to take a decision, only considers the current environment state.

\begin{tabular}{|c|c|}
\hline Related Concept & Activity description \\
\hline Development of EDFA & Put the steps of a process in the correct order \\
\hline Advantages of EDFA & Classify sentences either true or false \\
\hline Limitation of EDFA & Choose the correct answer to complete properly a timeline of events \\
\hline EDFA working process & Organize the information into a hierarchical order \\
\hline Stimulated Emission & Select an image for a key reason related to the learning content \\
\hline Spontaneous Emission & $\begin{array}{l}\text { Choose the most appropriate device to be used in a real world project } \\
\text { situation }\end{array}$ \\
\hline Energy Absorption & Summarize the advantages comparing the new technology to the old one \\
\hline Properties of erbium & Complete a process diagram properly \\
\hline EDFA base parameters & Read a passage and fill in the blanks with the most suitable words \\
\hline Pumping Laser & $\begin{array}{l}\text { Solve a problem based on the previous knowledge about the concept } \\
\text { associated }\end{array}$ \\
\hline Erbium Doped Fiber length & $\begin{array}{l}\text { Watch a task (a sequence of images) and determinate if the task was done } \\
\text { correctly }\end{array}$ \\
\hline The erbium organization & Pug in pictures into a system and analyze the effects \\
\hline The EDFA behavior & Point the mistakes presented in an illustration \\
\hline The amplifier saturation & Prepare a training program about a subject by choosing the related concepts \\
\hline
\end{tabular}

Table 2 - Interaction Conceptual Model 
The interaction between the agent and the student is also a way to bring up the motivational and emotional elements related to the communication between a human tutor and a learner [17]-[18]. In this project, it was created an interaction conceptual model based on the activities that the user should do. Table II summarizes the interactions proposed by the agents.

Another important task in the development of the proposed learning resource is the strategy to give feedback to the student after interacting with the agents. The following principles were taken to prepare the feedbacks [19]:

- The students should be given the knowledge of results. That is to say, to inform them if the answer is correct or not immediately after they answer the question;

- The students should be presented the explanation of why the answer is correct or incorrect. This is a way of learning new concepts whether the answer is correct or not;

- The students should be presented a way to learn the related concept if the answer is incorrect. By this time the agent shall act in the virtual learning environment in order to propose the study of the associated learning object.

The agents were developed using the software Adobe Flash [20], which is a popular tool on Internet, frequently used to create animations, 98\% of Internet-enabled desktops have Flash Player available [21]. Flash is a tool based on vector graphics, it is recommended for creation of learning objects, because the Action Script language available with Flash version 5, allows better controls and gives support to build sophisticated applications, adding intelligent interactivity, formulas and mathematical calculations and special effects that contribute to keep the students attention. Finally, the agents were added to the concept map.

\subsection{Learning Objects}

The development of the learning objects can be summarized by basically two principle designs. The first one is related to the multimedia expertise to create audio and animations. The second one is the insertion of interactive resources that requires the definition of an activity model to describe how the communication between the tutoring system and the user will take place.

The animation of each learning object was developed in a way to generate a user friendly interface exploring the use of colors and graphics. However, an optimization criteria was taken in order to avoid cognitive overload that might lead the learners to negative feelings about the instructional digital tool [6].

Still according to [6], the learning process based on multimedia resources can be optimized if the corresponding words and pictures are presented near and simultaneously. It makes the students feel more comfortable because it is possible to hold the presented information in the working memory at the same time. Another important point that was considered in the learning object development process is to eliminate unneeded or irrelevant words, pictures or sounds. The use of unneeded information can divert attention from the important concepts and might lead the learner to organize the information around an inappropriate theme [6]. As the aim of the learning object is to distribute information quickly, straight to the point of interest, the level of interaction was limited to choosing an option or rollovers.

The EDFA learning object was build up on top of Adobe Flash, then the eXe eLearning XHTML [22] editor was used to generate metadata and wrapping up EDFA learning object content developed in Adobe Flash. The objective of the usage of those tools is to aid the development of digital educational resources and its publication on Internet websites without the knowhow about web publishing or programming. Moreover the eXe eLearning tool can easily package the resources according to SCORM 1.2, IMS LD or a simple website. Each SCORM package was loaded as an activity in LCMS MOODLE platform, to be integrated with other educational resources. 


\subsection{Computer Simulation Activity}

Due to the complex physics concepts represented by mathematical models related to the optical communication systems, the use of computer simulation tools is being used in different contexts, such as scientific researches, development of new industrial products or project technical specifications, in order to analyze the behavior of a photonic device. Facing the relevance of using a simulation software tool, the Photonic Transmission Design Suite [16] was developed not only for the optimization and analysis of photonic devices like EDFA, but for the optimization of an optical system with all its elements.

In order to help students before and during the computer simulation activity, it was developed the simulation instruction module as shown in figure 2. It consists of providing instructions of how to use the PTDS software as well as a guideline for the activities related to EDFA proposed by PTDS simulation tool [23].

The initial instructions include information about the development of the PTDS software by VPI [14], followed by the download and installation procedure of the demonstrative version of the PTDS software from the MOODLE platform. The simulation instruction module also provides information of how to navigate on this software, from selecting an activity to changing parameters of a system or exporting results. The simulation instruction module was also developed using Adobe Flash [20] and it was implemented in MOODLE platform [16].

\section{RESULTS AND DISCUSSION}

The navigation through the learning resource proposed can be divided into two steps. The first part of the study is the use of the concept map and the learning objects, when necessary. The last part is the use of the PTDS simulation tool. The use of the learning resource proposed begins with the initial instructions as shown in figure 4. The initial instruction module presents the aim of the study, the essential prerequisites for the appropriate use of the system and also it provides information of how to exploit the concept map and the learning objects.

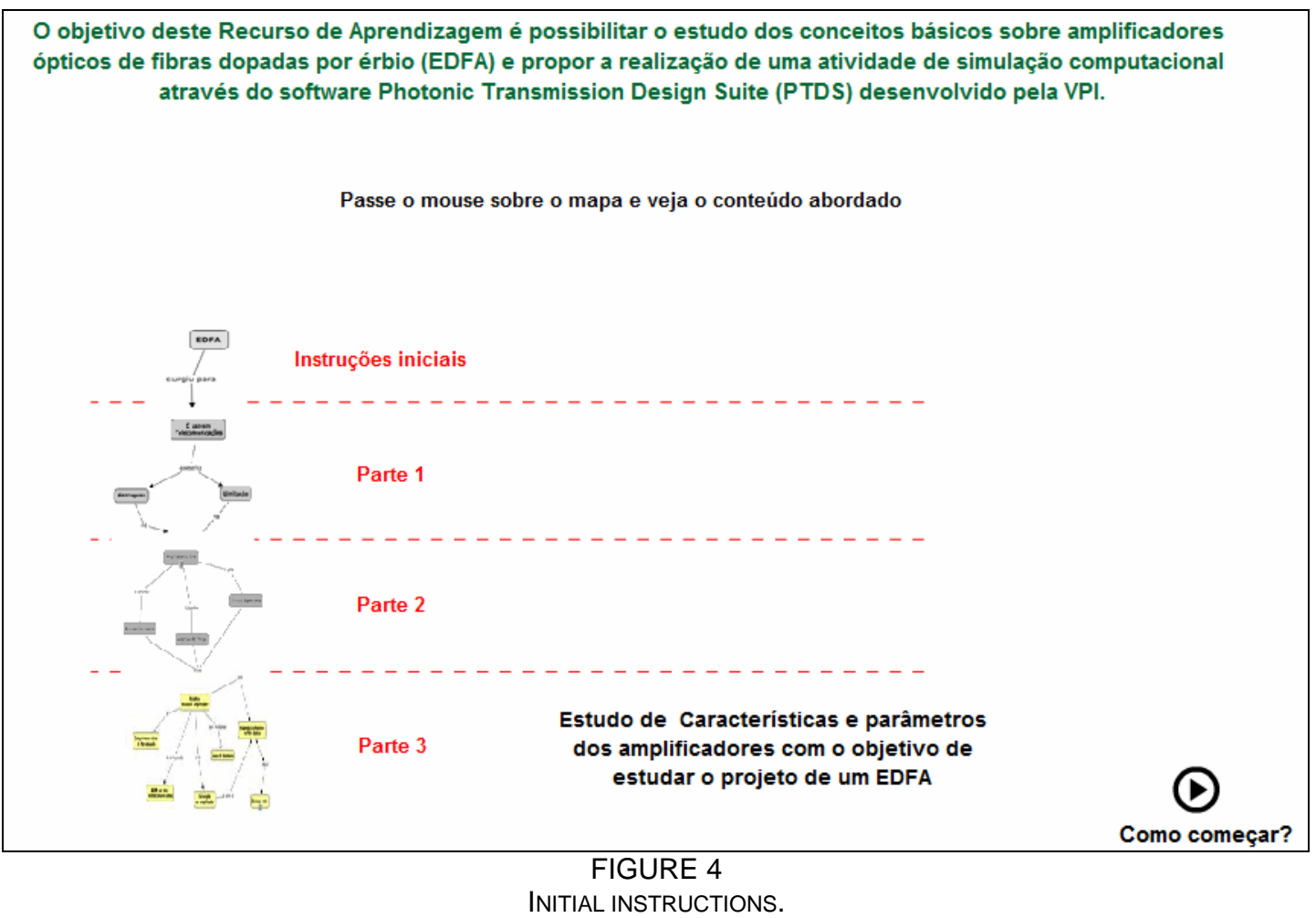


Although the initial instruction module makes clear that the use of the concept map should be done according to the hierarchical order, it is important to highlight the strategy of using different colors in the development of the map for each hierarchical group. In figure 5, the graphical knowledge representation of the concepts related to EDFA can be seen.

The agents added to each label in the map can contribute to the flexibility of the learning resource. The main aim of the interaction between the agent and the learner is to collect information about the user background, but the strategy taken also allows the student to have an appropriate feedback of his/her answers as well as to learn complementary information from the correct or incorrect answers. Figure 6 shows the agent related to the properties of the erbium ion. The techniques used for developing the multimedia animations are a way to stimulate the meaningful learning, as shown in figure 7.

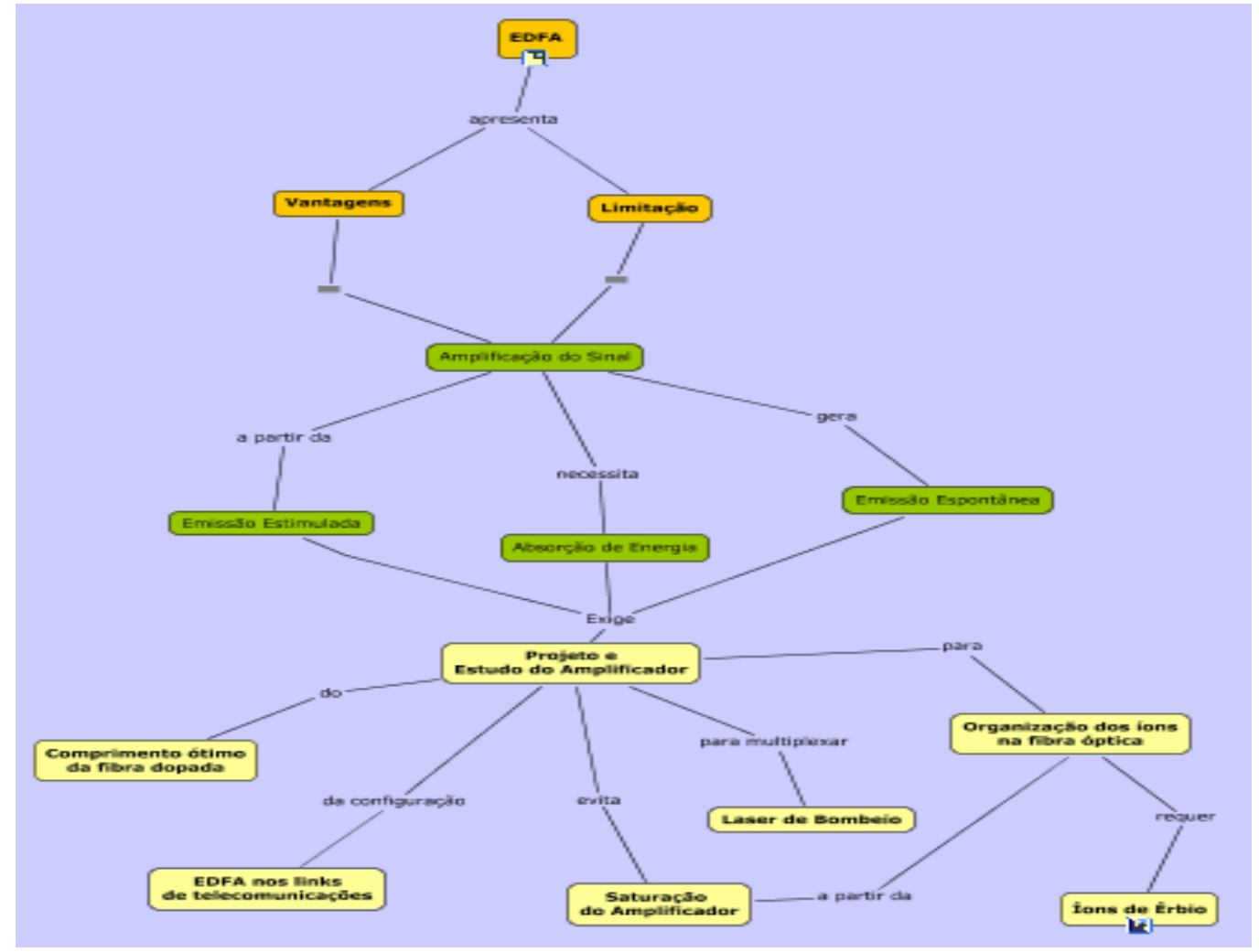

FIGURE 5

EDFA CONCEPT MAP.

In addition to the multimedia resources, the interactivity inserted on the learning objects is also a way to optimize the learning process, leading the students to be active on the process. Figure 7 shows the interaction with an agent. 


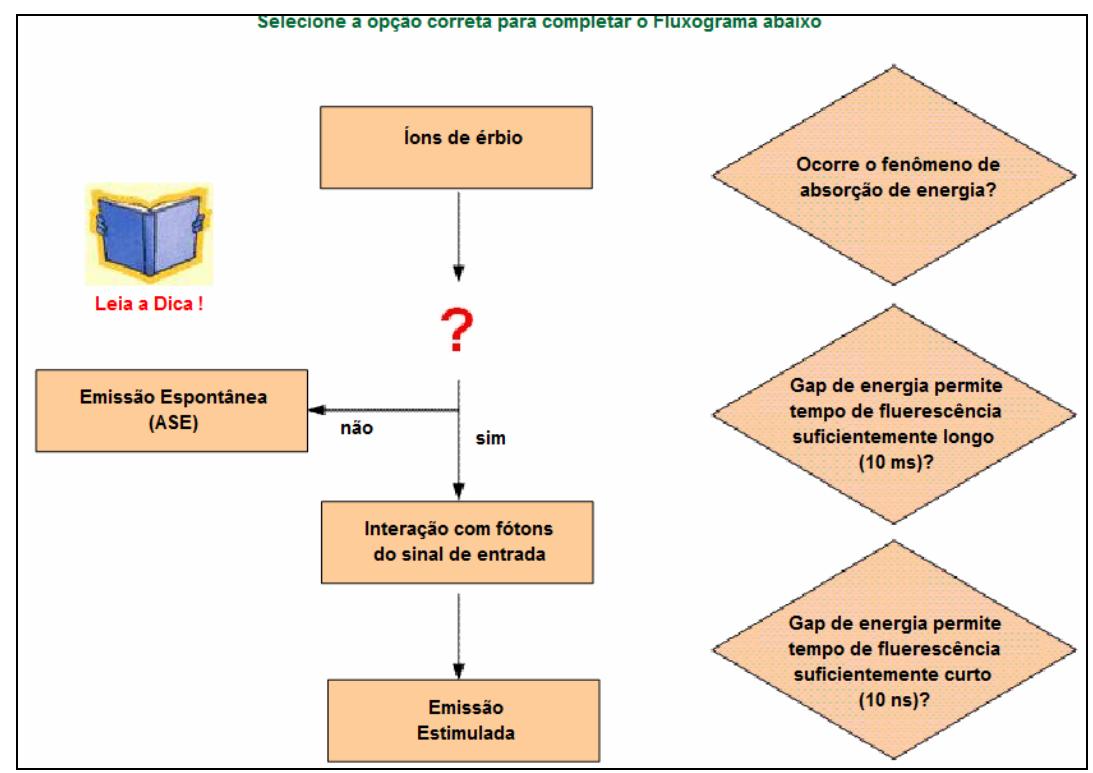

FIGURE 6

AgENT EXAMPLE.

Finally, for the last part of the navigation through the learning resource, it is expected to have the users with a minimum background about the EDFA base concepts. It does not matter if such knowledge is a result of previous background or the study provided by the learning objects.

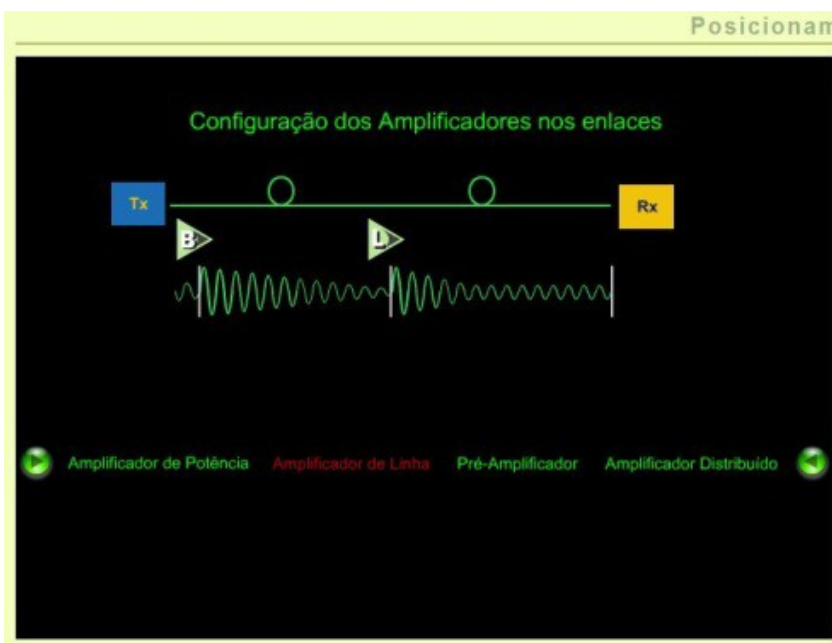

FIGURE 7

LEARNING OBJECT.

The simulation activity is an opportunity to get to an advanced knowledge level about the erbium doped fiber amplifiers and it is also a tool that can be used in real world projects. 


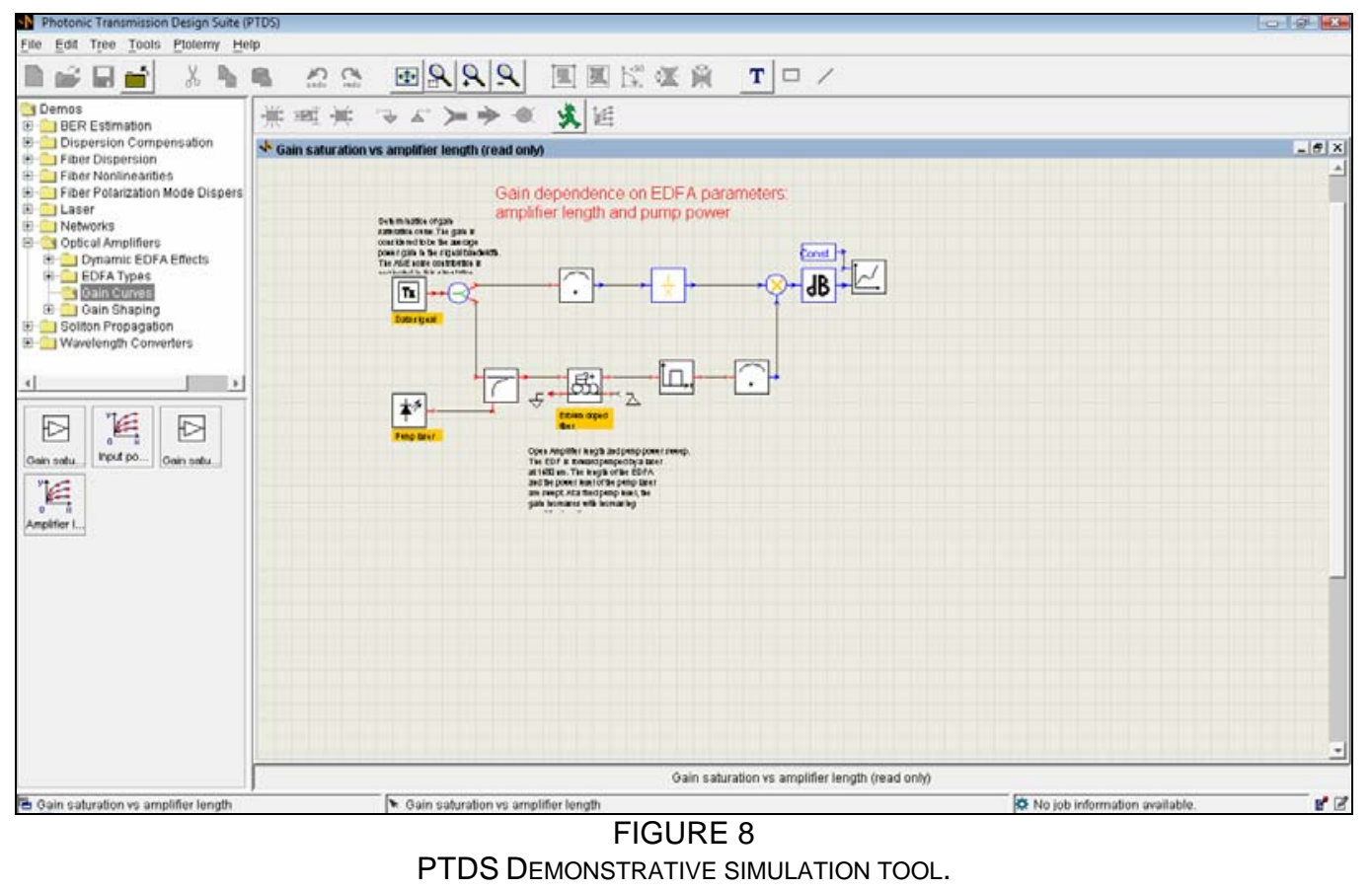

Figure 8 shows the interface of the software PTDS which helps students to get used to the optical telecommunication project parameters.

\section{CONCLUSIONS AND FURTHER WORKS}

The insertion of rational computer agents in the conceptual map permitted not only the adaptation of the system but also the increase of the reusability of the learning resource, which can be used by a wide range of students, either for beginner under graduating students or graduating students.

The navigation through the conceptual map and the learning objects allows the optimization of the computer simulation tool leading the users to fulfill the lack of concepts related to EDFA by accessing the associated learning objects. The use of concept maps as well as the learning objects based on multimedia and interactive technologies are also a strategy towards the achievement of the meaningful learning.

The successful implementation of the learning resource proposed suggests as further works, the development of complementary learning objects, exploiting other topics related to the photonics and optical communication systems, and the evaluation of the learning resource with students in a real world situation.

\section{ACKNOWLEDGMENTS}

The authors of this paper thank MackPesquisa for sponsoring this research.

\section{REFERENCES}

[1] IEEE LTSC WG 12. 2003. Available: <http://ltsc.ieee.org/ wg12/>.

[2] Wiley, D. A. "Learning Object Design and Sequencing Theory," PhD Thesis, Brigham Young University. Provo, USA, 2000.

[3] Mustaro, P.N.; Silveira, I.F; Omar, N.; Stump, S.M.D. "Structure of Storyboard for Interactive Learning Objects Development", In Koohang, A. \& Harman, K. (Eds.), Learning Objects and Instructional Design (pp. 253-280), Santa Rosa, California, Informing Science Press, 2007. 
[4] Graf, S.; List, B. "An Evaluation of Open Source E-Learning Platforms Stressing Adaptation Issues", Vienna, 2002, Available: http://www.campussource.de/aktuelles/docs/icalt2005.pdf

[5] ADL - Advanced Distributed Learning, Available: http://www.adlnet.org

[6] Mayer, R. "Multimedia Learning", Santa Barbara, Cambridge University Press, 2001.

[7] Preece, J. Rogers, Y. Sharp, H. "Interaction Design: beyond human-computer interaction". Wiley, 2002.

[8] Novak, J. D. Gowin, D. B. Learning how to learn. Cambridge University Press, NY, 1984.

[9] Cañas, A. Carvalho, M. "Concept Maps and Al: an unlikely marriage?". In: Brazilian Journal of Computer in Education. Volume 13. 2005.

[10] Lévy, P. “Les Technologies de l'intelligence”, La Dácouverte, Paris, 1990.

[11] Nahvi, M. "Dynamics of Student-computer Interaction in a Simulation Environment: Reflections on curricular issues". In: Proceedings of Frontiers in Education, 1996.

[12] Weiss, G. "Multiagent Systems", MIT Press, 2000.

[13] Norvig, P. Russel, S. Artificial Intelligence: A modern approach. Prentice Hall, 2002.

[14]VPIphotonics: Photonic Design and Simulation Software, 2009, Available in: http://www.vpiphotonics.com/

[15] Cmap Tools, 2009, Available in: http://cmap.ihmc.us/

[16] Moodle: A Free, Open Source Course Management System for Online Learning, Disponível em: http://moodle.org/

[17] Pinker, S. How the mind works. W. W. Norton \& Company, 1998.

[18] Cleary, C. Schank, R. Engines for Education. Lawrence Erlbaum Associates, New Jersey, 1995.

[19] Development of Interactive Multimedia Instruction (IMI) part 3 of 5. US Department of Defense Handbook, 2001.

[20] Adobe Flash Interactive Multimedia, Interactive Design, 2008, Available: http://www.adobe.com/products/flash/

[21] Flash Player Penetration. "Adobe - Flash Player Statistics". Available: http://www.adobe.com/products/player_census/flashplayer/

[22] eXe eLearning XHTML editor. Available: http://exelearning.org/

[23] Photonic Modules Reference Manual, A demonstration version of PTDS for windows. VPI, 1999. 